\title{
Development and optimization of metoprolol succinate gastroretentive drug delivery system
}

\author{
SANJAY P. BOLDHANE ${ }^{1, *}$ \\ BHANUDAS S. KUCHEKAR ${ }^{2}$ \\ 1 Piramal Health Care Limited \\ Mumbai-400063, India \\ ${ }^{2}$ Maharashtra Institute of Pharmacy \\ Pune-411038, India
}

Accepted August 30, 2010

\begin{abstract}
Metoprolol succinate (MS) gastroretentive (GR) controlled release system was formulated to increase gastric residence time leading to improved drug bioavailability. Box-Behnken model was followed using novel combinations of sodium alginate (SA), sodium carboxymethylcellulose (NaCMC), magnesium alumino metasilicate (MAS) as independent variables. Floating lag time (Flag), $t_{25}$, $t_{50}, t_{75}$, diffusion exponent as dependent variables revealed that the amount of $\mathrm{SA}, \mathrm{NaCMC}$ and MAS have a significant effect $(p<0.05)$ on $t_{25}, t_{50}, t_{75}$ and Flag. MSGR tablets were prepared and evaluated for mass, thickness, hardness, friability, drug content and floating property. Tablets were studied for dissolution for $24 \mathrm{~h}$ and exhibited controlled release of MS with floating for $16 \mathrm{~h}$. The release profile of the optimized batch MS01 fitted first-order kinetics $\left(R^{2}=0.9868, n=0.543\right)$, indicating non-Fickian diffusion or anomalous transport by diffusion and swelling.
\end{abstract}

Keywords: metoprolol succinate, gastroretention, Box-Behnken design, floating tablets, release kinetics, controlled release

Gastric retention will provide advantages such as delivery of drugs with narrow absorption windows in the small intestinal region, namely proximal parts of the gastrointestinal tract (stomach and/or duodenum). Pharmaceutical dosage forms which remain in stomach for a prolonged period of time after oral administration and release the active ingredient in a controlled manner are important for the delivery of a wide variety of drugs (1-5).

Metoprolol succinate (MS) is a $\beta 1$-selective adrenergic blocking agent (6). Since the half-life of MS is $\sim 3$ to $4 \mathrm{~h}$ (7), multiple doses are needed to maintain a constant plasma concentration for a good therapeutic response and improved patient compliance. It has also been reported that MS absorption mainly takes place in the duodenum and jejunum and is directly proportional to the dose available (8). A gastroretentive is particularly useful for drugs that are primarily absorbed in the duodenum and upper jejunum seg-

\footnotetext{
* Correspondence; e-mail: sanjayboldhane@hotmail.com
} 
ments (9). MS is highly soluble throughout physiological $\mathrm{pH}$. Drug solubility was 157 $\mathrm{mg} \mathrm{mL}^{-1}$ in water $(\mathrm{pH}=5.5)$ and $183 \mathrm{mg} \mathrm{mL}^{-1}$ in $0.1 \mathrm{~mol} \mathrm{~L}^{-1} \mathrm{HCl}$ solution $(\mathrm{pH}=1.0)$. It is therefore a suitable candidate with high solubility for a monolithic system (10).

The present study involves the design and optimization of a novel gastroretentive, floating, swellable, controlled release tablet by combining three polymers with different concentrations: sodium alginate (SA) - rapidly hydrating, rate controlling polymer, sodium carboxymethylcellulose (NaCMC) - gel forming agent, and magnesium alumino metasilicate (MAS) - swelling controlling agent. Furthermore, calcium sulphate dihydrate (CS) - cross linker, gel strength enhancer for SA, and sodium bicarbonate (SBC) as a gas generating agent were also used. The combined effect of these polymers on the floating behaviour and on in vitro release pattern of the MS has also been evaluated.

\section{EXPERIMENTAL}

\section{Materials}

Metoprolol succinate was received as a gift sample from Alembic Ltd., India. SA was purchased from Anshul Agencies and NaCMC from Auqualon, India. CS was purchased from JRS Pharma and SBC from S.D. Fine-Chem Ltd., India. MAS was purchased from Gangwal Chemicals, India. All the other chemicals used were of analytical grade.

\section{Methods}

Calibration curves of MS were determined in $0.1 \mathrm{~mol} \mathrm{~L}^{-1} \mathrm{HCl}$ and in methanol at $\lambda=222 \mathrm{~nm}(R=0.9932$ and 0.9982 , respectively), using a UV-Visible spectrophotometer (Lambda 25, Perkin-Elmer, USA). The calibration curve in $0.1 \mathrm{~mol} \mathrm{~L}^{-1} \mathrm{HCl}$ was used for dissolution studies while drug content was determined using the calibration curve in methanol.

\section{Preparation of MSGR tablets}

MSGR tablets were prepared according to the composition of optimized batches (Table I). MSGR tablets (200 mg) were prepared by the direct compression method. Initially, all ingredients were sieved through $425-\mu \mathrm{m}$ sieve opening, weighed and mixed for $10 \mathrm{~min}$ in a planetary mixer (Kenwood PM 900, UK) at $10 \mathrm{rpm}$. The drug was mixed with SA, NaCMC, MAS, SBC and CS. Finally, the MAS was added as a lubricant and mixed for additional 2-3 min. Tablets were compressed on a tabletting machine (Minipress by Clit, 10 stations, Chamunda Pharma Machinary Pvt. Ltd., India) fitted with a 10.4-mm circular shaped standard concave punch with tableting force of $(3.5 \pm 0.5) \times 10^{3} \mathrm{~kg}$.

\section{Characterization of MSGR tablets}

The prepared MSGR tablets were tested for physical characteristics, viz., mass variation, thickness (measured using a Vernier caliperse, Mitutoyo Corporation, Japan), hardness (measured with a hardness tester, Erweka, Germany) and friability (determined using a Roche friabilator, Germany). 
S. P. Boldhane and B. S. Kuchekar: Development and optimization of metoprolol succinate gastroretentive drug delivery system, Acta Pharm. 60 (2010) 415-425.

Table I. MSGR tablet composition

\begin{tabular}{ccccc}
\hline Formulation batch & CS $(\%)$ & SA $(\%)$ & NaCMC $(\%)$ & MAS $(\%)$ \\
\hline MSO1 & 25.7 & 15.0 & 15.0 & 5.0 \\
MSO2 & 35.7 & 10.0 & 10.0 & 5.0 \\
MS03 & 25.7 & 20.0 & 10.0 & 5.0 \\
MS04 & 25.7 & 10.0 & 20.0 & 5.0 \\
MS05 & 15.7 & 20.0 & 20.0 & 5.0 \\
MS06 & 35.7 & 10.0 & 15.0 & - \\
MS07 & 25.7 & 20.0 & 15.0 & - \\
MS08 & 25.7 & 10.0 & 15.0 & 10.0 \\
MS09 & 15.7 & 20.0 & 15.0 & 10.0 \\
MS10 & 35.7 & 15.0 & 10.0 & - \\
MS11 & 25.7 & 15.0 & 20.0 & - \\
MS12 & 25.7 & 15.0 & 10.0 & 10.0 \\
MS13 & 15.7 & 15.0 & 20.0 & 10.0 \\
MS14 & 25.7 & 30.0 & - & 5.0 \\
MS15 & 25.7 & - & 30.0 & 5.0 \\
MS16 & 30.7 & 15.0 & 15.0 & - \\
\hline
\end{tabular}

CS - calcium sulphate dihydrate, SA - sodium alginate, NaCMC - sodium carboxymethylcellulose, MAS magnesium aluminium metasilicate.

All batches contain $33.3 \%$ MS, $5.0 \%$ SBC and $1 \%$ magnesium stearate.

Total tablet mass is $600.0 \mathrm{mg}$.

\section{Drug content}

Accurately weighed MSGR tablets (10 tablets) were crushed to form a fine powder. An accurately weighed quantity equivalent to $200 \mathrm{mg}$ of MS was transferred to a $100-\mathrm{mL}$ volumetric flask. To this, $50 \mathrm{~mL}$ methanol was added and sonicated for $15 \mathrm{~min}$. Volume was made up to the mark with methanol. The solution was filtered through a $0.45-\mu \mathrm{m}$ filter and $1 \mathrm{~mL}$ of this solution was diluted to $50 \mathrm{~mL}$ with methanol. Absorbance was measured at $222 \mathrm{~nm}$.

\section{In vitro dissolution studies}

The release rate of MSGR tablets $(n=3)$ was determined with a USP dissolution apparatus-II (paddle method) using $75 \mathrm{rpm}$ speed and $900 \mathrm{~mL}$ of $0.1 \mathrm{~mol} \mathrm{~L}^{-1} \mathrm{HCl}$ as dissolution medium at $37 \pm 0.5^{\circ} \mathrm{C}(11)$. A sample (10 mL of the solution) was withdrawn from the dissolution apparatus (Electrolab, India) at regular time intervals up to $24 \mathrm{~h}(1,2,4$, $6,8,10,12,16,20$ and $24 \mathrm{~h}$ ) and replaced with the same volume of fresh dissolution medium. The samples were filtered through a $0.45-\mu \mathrm{m}$ membrane filter and diluted to a suitable concentration with $0.1 \mathrm{~mol} \mathrm{~L}^{-1} \mathrm{HCl}$, and the absorbance of these solutions was measured at $222 \mathrm{~nm}$. Cumulative percentage of drug release was calculated using the equation obtained from a standard curve. 


\section{In vitro buoyancy studies}

The in vitro buoyancy studies were performed by measuring the floating lag times according to the method of Rosa et al. (12). The tablets were placed in a 100-mL beaker containing $0.1 \mathrm{~mol} \mathrm{~L}^{-1} \mathrm{HCl}$. The time required for the tablet to rise to the surface and float was defined as the floating lag time (Flag).

\section{Box-Behnken design}

Statistical analysis of the Box-Behnken design batches was performed by multiple linear regression analysis using SYSTAT 12. A Box-Behnken design was constructed to study the effect of the independent variables, viz., the amount of SA $\left(\mathrm{X}_{1}\right)$, the amount of $\operatorname{NaCMC}\left(\mathrm{X}_{2}\right)$ and the amount of MAS $\left(\mathrm{X}_{3}\right)$ on dependent variables like $t_{25}, t_{50}, t_{75}$, Flag of MSGR tablets.

\section{RESULTS AND DISCUSSION}

\section{Physical characterization of the tablets}

Tablet mass of all the formulations was found to be $600.0 \pm 20.0 \mathrm{mg}$. Tablet thickness was found to be $6.0 \pm 0.1 \mathrm{~mm}$. The hardness of the formulation was 70 to $90 \mathrm{~N}$, indicating satisfactory mechanical strength. Percentage mass loss in the friability test was 0.2 to $0.5 \%$ in all cases, which was an indication of good mechanical resistance of the tablet. Tablets of all the prepared batches containing MS were found to be within $100.0 \pm 5.0 \%$ of the labelled content, indicating content uniformity of the prepared formulations.

\section{In vitro dissolution studies}

Batch MS01 released $75 \%$ of MS in $16 \mathrm{~h}$ with Flag of $48 \mathrm{~s}$ compared to batch MS13 which showed $75 \%$ MS release in $16 \mathrm{~h}$ and the Flag of $540 \mathrm{~s}$, and batch MS02 with a Flag of $45 \mathrm{~s}$ and $t_{75}$ of $10.2 \mathrm{~h}$. Based on this data, batch MS01 was considered the best formulation with desirable Flag, therefore this formulation was selected for factorial studies to optimize the formulation and to study the effects of variables on the formulation (Tables II and III). Prepared batches show variation in drug release due to different concentrations of polymers used during their preparation (Fig. 1).

\section{In vitro buoyancy studies}

The results of in vitro buoyancy studies showed quick floating of the tablet within $2 \mathrm{~min}$ after placing the tablet in dissolution medium. Studies showed that no single polymer individually was sufficient to produce buoyancy and integrity of the tablet. Flag varied between $45 \mathrm{~s}$ to $15 \mathrm{~min}$ (Table II). Buoyancy mainly depended upon the quantity of MAS and SBC. SBC of $5 \%$ was found optimal with optimum integrity and controlled release profile of the drug from the tablet. MAS produces swelling of the tablet while SBC has the ability to generate gas in the presence of hydrochloric acid, which gets entrapped in the tablet. This leads to reduction in the density of the tablet, thereby producing floating. 


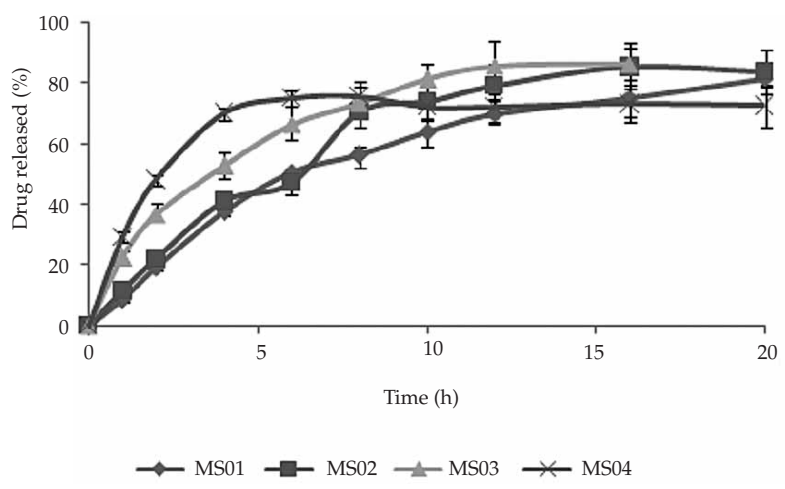

Fig. 1. MSGR tablets dissolution profile of batches MS01 to MS04. Mean \pm SD, $n=3$.

In case of batches MS01 and MS02, the MAS quantity of $5.0 \%$ produced Flag of $48 \mathrm{~s}$ and $45 \mathrm{~s}$, respectively, while in batch MS13, the quantity of MAS of $10.0 \%$ produced Flag of $540 \mathrm{~s}$. The combination of polymer SA and NaCMC with CS showed integrity of the system and produced buoyancy in a minimum of time. These hydrophilic polymers hydrate and swell rapidly due to the imbibing of the gastrointestinal fluid by the tablet, density of the tablet is lowered due to swelling and gas formation which helps in system buoyancy.

Table II. MSGR tablet-optimization batches in the Box-Behnken design

\begin{tabular}{|c|c|c|c|c|c|c|c|}
\hline \multirow{2}{*}{ Batch code } & \multicolumn{3}{|c|}{ Coded factor level ${ }^{\#}$} & \multirow{2}{*}{$t_{25}(\min )^{\mathrm{a}}$} & \multirow{2}{*}{$t_{50}(\min )^{\mathrm{a}}$} & \multirow{2}{*}{$t_{75}(\min )^{a}$} & \multirow{2}{*}{ Flag $(\mathrm{s})^{\mathrm{a}}$} \\
\hline & $x_{1}$ & $x_{2}$ & $x_{3}$ & & & & \\
\hline MS01 & 0 & 0 & 0 & $180 \pm 0$ & $360 \pm 0$ & $960 \pm 0$ & $48 \pm 1$ \\
\hline MS02 & -1 & -1 & 0 & $132 \pm 0$ & $390 \pm 0$ & $612 \pm 0$ & $45 \pm 1$ \\
\hline MS03 & 1 & -1 & 0 & $72 \pm 0$ & $228 \pm 0$ & $492 \pm 0$ & $>1800 \pm 10$ \\
\hline MS04 & -1 & 1 & 0 & $48 \pm 0$ & $132 \pm 0$ & $360 \pm 0$ & $100 \pm 4$ \\
\hline MS05 & 1 & 1 & 0 & $110 \pm 0$ & $228 \pm 0$ & $450 \pm 0$ & $420 \pm 3$ \\
\hline MS06 & -1 & 0 & -1 & $48 \pm 0$ & $132 \pm 0$ & $348 \pm 0$ & $900 \pm 6$ \\
\hline MS07 & 1 & 0 & -1 & $42 \pm 0$ & $108 \pm 0$ & $348 \pm 0$ & $1320 \pm 13$ \\
\hline MS08 & -1 & 0 & 1 & $120 \pm 1$ & $336 \pm 0$ & $690 \pm 0$ & $900 \pm 5$ \\
\hline MS09 & 1 & 0 & 1 & $132 \pm 1$ & $330 \pm 0$ & $690 \pm 0$ & $390 \pm 6$ \\
\hline MS10 & 0 & -1 & -1 & $30 \pm 1$ & $48 \pm 0$ & $132 \pm 0$ & $780 \pm 7$ \\
\hline MS11 & 0 & 1 & -1 & $72 \pm 0$ & $144 \pm 0$ & $360 \pm 0$ & $485 \pm 4$ \\
\hline MS12 & 0 & -1 & 1 & $126 \pm 0$ & $348 \pm 0$ & $660 \pm 0$ & $320 \pm 8$ \\
\hline MS13 & 0 & 1 & 1 & $120 \pm 0$ & $270 \pm 0$ & $960 \pm 0$ & $540 \pm 5$ \\
\hline
\end{tabular}

${ }^{\mathrm{a}}$ Mean $\pm \mathrm{SD}, n=3$. 
S. P. Boldhane and B. S. Kuchekar: Development and optimization of metoprolol succinate gastroretentive drug delivery system, Acta Pharm. 60 (2010) 415-425.

Table III. Translation of coded levels into actual values

\begin{tabular}{cccc}
\hline \multirow{2}{*}{ Coded level } & \multicolumn{3}{c}{ Actual value (\%) } \\
\cline { 2 - 4 } & $\mathrm{X}_{1}$ & $\mathrm{X}_{2}$ & $\mathrm{X}_{3}$ \\
\hline-1 & 10 & 10 & 0 \\
0 & 15 & 15 & 5 \\
1 & 20 & 20 & 10 \\
\hline
\end{tabular}

$\mathrm{X}_{1}, \mathrm{X}_{2}, \mathrm{X}_{3}-$ conc. of SA, NaCMCS and MAS, respectively (\%).

\section{Effect of the release modulating agent and swelling morphology}

Effect of $5-10 \%$ of MAS that increased the Flag and controlled the release profile was studied. This was due to its extremely fine, porous nature, which allows the medium to penetrate into the tablet through the small holes in its particles, leading to reduction in tablet density and producing swelling that increases the Flag. Medium uptake by the tablet was determined in $0.1 \mathrm{~mol} \mathrm{~L}^{-1} \mathrm{HCl}$. MSGR tablet showed rapid hydration and gelling intact up to $12 \mathrm{~h}$.

\section{Kinetics of drug release}

Sigma Plot 10 was used for controlled release curve fitting to select the most appropriate model. The dissolution data for batch MS01 was fitted to the Bekker-Lonsdale, first-order, Higuchi, Hixson-Crowell and Korsmeyer-Peppas models (13-15). The release profile of the optimized batch MS01 fitted best to the first-order $\left(R^{2}=0.9868\right.$ and $n=$ 0.543), indicating non-Fickian diffusion or anomalous transport, with release by diffusion and swelling (combination of diffusion and erosion-controlled release). Nevertheless, the Korsmeyer-Peppas model has also shown a good coefficient of determination (Table IV).

\section{Box-Behnken design}

The dependent variables chosen were the times required for 25, 50 and $75 \%$ the cumulative drug release and Flag; the results showed a wide variation (Table II). The data clearly indicate that the values of $t_{25}, t_{50}, t_{75}$ and Flag are strongly dependent on the in-

Table IV. Kinetic modeling of drug release

\begin{tabular}{cc}
\hline Curve fitting with model/equation & $R^{2}$ \\
\hline First-order & 0.9868 \\
Hixon-Crowell & 0.9588 \\
Higuchi & 0.9688 \\
Baker-Lonsdale & 0.9517 \\
Korsmeyer-Peppas & 0.9716 \\
$n$ & 0.5430 \\
\hline
\end{tabular}


S. P. Boldhane and B. S. Kuchekar: Development and optimization of metoprolol succinate gastroretentive drug delivery system, Acta Pharm. 60 (2010) 415-425.

dependent variables, viz. the amount of SA $\left(X_{1}\right)$, the amount of $\operatorname{NaCMC}\left(X_{2}\right)$ and the amount of MAS $\left(X_{3}\right)$. The resultant equations of all responses are given below:

$$
\begin{aligned}
& t_{25}=-460.0+35.6 X_{1}+36.65 X_{2}+31.75 X_{3}+1.22 X_{1} X_{2}+0.18 X_{1} X_{3}-0.48 X_{2} X_{3}- \\
& 1.82 X_{1}^{2}-1.76 X_{2}^{2}-1.96 X_{3}^{2}\left(R^{2}=0.994\right) \\
& t_{50}=-284.25+12.9 X_{1}+47.7 X_{2}+79.8 X_{3}+2.58 X_{1} X_{2}+0.18 X_{1} X_{3}-1.74 X_{2} X_{3}- \\
& 1.83 X_{1}^{2}-2.79 X_{2}^{2}-3.51 X_{3}^{2}\left(R^{2}=0.989\right) \\
& t_{75}=-3960.75+301.05 X_{1}+293.25 X_{2}+106.8 X_{3}+0.90 X_{1} X_{2}+0.0 X_{1} X_{3}+0.72 X_{2} X_{3}- \\
& 10.41 X_{1}^{2}-10.05 X_{2}^{2}-7.23 X_{3}^{2}\left(R^{2}=0.980\right) \\
& \text { Flag }=1942.94 .75-265.01 X_{1}+78.98 X_{2}-210.40 X_{3}+2.72 X_{2}^{2}-9.30 X_{1} X_{3}+ \\
& 5.15 X_{2} X_{3}+9.25 X_{1}^{2}-4.59 X_{2}^{2}+23.92 X_{3}^{2}\left(R^{2}=0.982\right)
\end{aligned}
$$

The values obtained for the coefficient of determination indicate a good fit. The data demonstrate that both $X_{1}$ and $X_{2}$ affect the drug release $\left(t_{25}, t_{50}\right.$ and $\left.t_{75}\right)$. It may also be concluded that the low level of $X_{1}$ (amount of SA) and higher level of $X_{2}$ (amount of $\mathrm{NaCMC}$ ) favour preparation of gastroretentive-sustained release MS tablets. High values of the $X_{1} X_{2}$ coefficient also suggest that the interaction between $X_{1}$ and $X_{2}$ had a significant $(p<0.05)$ effect on $t_{25}, t_{50}$ and $t_{75}$. It can be concluded that the drug release pattern may be changed by appropriate selection of the $X_{1}, X_{2}$ and $X_{3}$ levels. The results in Table II reveal that batches MS02, MS08, MS09 and MS12 were close to the required attributes of gastroretentive tablets in terms of $t_{50}, t_{75}$ and Flag, while batch MS01 was ideal because of its controlled release profile for $16 \mathrm{~h}(960 \mathrm{~min})$ with the desirable Flag of $48 \mathrm{~s}$. This was, therefore, considered the best formulation among all the prepared formulations.

The fitted equations relating to the response at $t_{25}, t_{50}, t_{75}$ and Flag are shown in equations (5-8):

$$
\begin{aligned}
& t_{25}=520-64.2 \mathrm{X}_{1}-29.4 \mathrm{X}_{2}+6.38 \mathrm{X}_{1} \mathrm{X}_{2}+1.48 \mathrm{X}_{1}^{2}-0.8 \mathrm{X}_{2}^{2}-0.008 \mathrm{X}_{1} \mathrm{X}_{2}^{2}- \\
& 0.164 \mathrm{X}_{1}^{2} \mathrm{X}_{2}\left(R^{2}=0.874\right) \\
& t_{50}=2592.64-295.03 \mathrm{X}_{1}-155.83 \mathrm{X}_{2}+21.3 \mathrm{X}_{1} \mathrm{X}_{2}+7.95 \mathrm{X}_{1}^{2}-0.206 \mathrm{X}_{2}^{2}- \\
& 0.07 \mathrm{X}_{1} \mathrm{X}_{2}^{2}-0.552 \mathrm{X}_{1}^{2} \mathrm{X}_{2}\left(R^{2}=0.867\right) \\
& t_{75}=1481.78-385.45 \mathrm{X}_{1}-13.46 \mathrm{X}_{2}+37.62 \mathrm{X}_{1} \mathrm{X}_{2}+13.75 \mathrm{X}_{1}^{2}-9.65 \mathrm{X}_{2}^{2}+ \\
& 0.18 \mathrm{X}_{1} \mathrm{X}_{2}^{2}-1.404 \mathrm{X}_{1}^{2} \mathrm{X}_{2}\left(R^{2}=0.885\right)
\end{aligned}
$$

Flag $=-4344.0-1858.8 \mathrm{X}_{1}+2864.4 \mathrm{X}_{2}-100.03 \mathrm{X}_{1} \mathrm{X}_{2}+163.02 \mathrm{X}_{1}^{2}-137.96 \mathrm{X}_{2}^{2}+$ $10.48 \mathrm{X}_{1} \mathrm{X}_{2}^{2}-8.65 \mathrm{X}_{1}^{2} \mathrm{X}_{2}\left(R^{2}=0.891\right)$ 
S. P. Boldhane and B. S. Kuchekar: Development and optimization of metoprolol succinate gastroretentive drug delivery system, Acta Pharm. 60 (2010) 415-425.

Values of the coefficients of determination indicate a good fit. As seen from the above equations, the individual factors, i.e., the amount of $S A\left(X_{1}\right)$ and the amount of $\operatorname{NaCMC}\left(\mathrm{X}_{2}\right)$ had a negative effect on $t_{25}, t_{50}$, and $t_{75}$ but in combination $\left(\mathrm{X}_{1} \mathrm{X}_{2}\right)$ showed a significant $(p<0.05)$ positive effect. In case of Flag, $X_{1}$ showed a negative effect (decreasing floating lag time) whereas $X_{2}$ had a positive effect (increasing floating lag time) while in combination they showed a negative effect (Fig. 2).

The following equations (9-12) show the effect of $X_{1}$ and $X_{3}$ on $t_{25}, t_{50}, t_{75}$ and Flag:

$t_{25}=51.605-1.299 X_{1}-3.715 X_{3}+3.407 X_{1} X_{3}+0.033 X_{1}^{2}-1.415 X_{3}^{2}+0.014 X_{1} X_{3}^{2}-$

$0.113 \mathrm{X}_{1}^{2} \mathrm{X}_{3}\left(R^{2}=0.942\right)$

$t_{50}=154.843-5.639 X_{1}+36.785 X_{3}+2.066 X_{1} X_{3}+0.106 X_{1}^{2}-3.537 X_{3}^{2}+0.071 X_{1} X_{3}^{2}-$

$0.086 \mathrm{X}_{1}^{2} \mathrm{X}_{3}\left(R^{2}=0.950\right)$

$t_{75}=287.407-1.763 X_{1}-179.24 X_{3}+34.446 X_{1} X_{3}+0.062 X_{1}^{2}-0.464 X_{3}^{2}-0.178 X_{1} X_{3}^{2}-$

$1.089 \mathrm{X}_{1}^{2} \mathrm{X}_{3}\left(R^{2}=0.853\right)$

Flag $=154.912+79.046 \mathrm{X}_{1}-375.13 \mathrm{X}_{3}-12.53 \mathrm{X}_{1} \mathrm{X}_{3}-1.420 \mathrm{X}_{1}^{2}+80.113 \mathrm{X}_{3}^{2}-$

$4.441 \mathrm{X}_{1} \mathrm{X}_{3}^{2}+1.607 \mathrm{X}_{1}^{2} \mathrm{X}_{3}\left(R^{2}=0.940\right)$

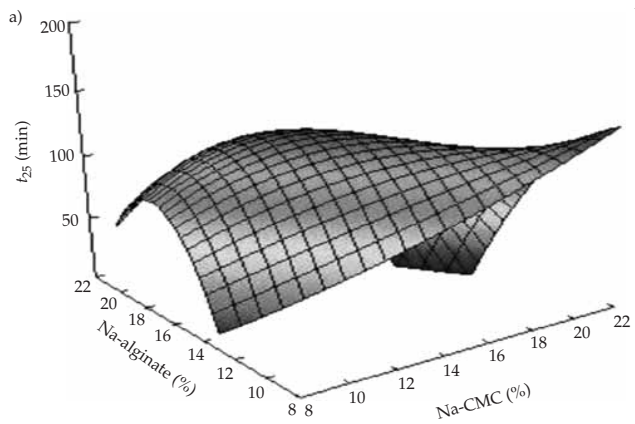

c)

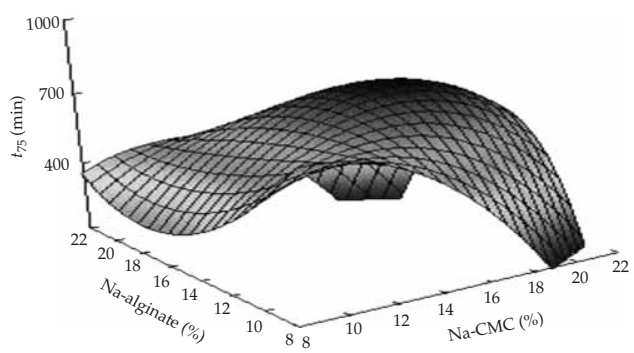



d)

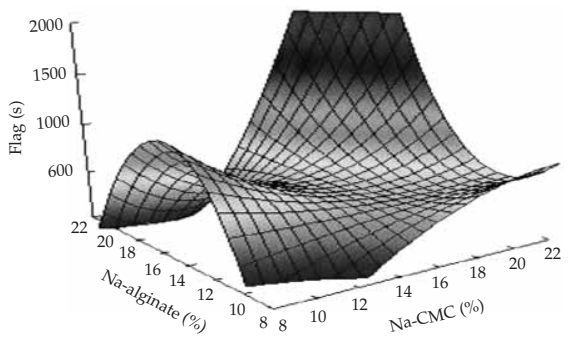

Fig. 2. Response surface plots of the concentration of $\mathrm{SA}\left(\mathrm{X}_{1}\right)$ and $\operatorname{NaCMC}\left(\mathrm{X}_{2}\right)$, vs. a) $\left.\left.t_{25}, \mathrm{~b}\right) t_{50}, \mathrm{c}\right) t_{75}$ and d) Flag. 
Individual factors $X_{1}$ and $X_{3}$ showed a negative effect on $t_{25}, t_{50}, t_{75}$ but their combination showed a significant $(p<0.05)$ positive effect. Flag $X_{1}$ showed a positive effect but $X_{3}$ had a negative effect.

The following equations (13-16) show the effect of $X_{2}$ and $X_{3}$ on $Y\left(t_{25}, t_{50}, t_{75}\right.$ and Flag):

$t_{25}=-185.00+28.20 \mathrm{X}_{2}+43.60 \mathrm{X}_{3}-1.04 \mathrm{X}_{2} \mathrm{X}_{3}-0.80 \mathrm{X}_{2}^{2}-3.640 \mathrm{X}_{3}^{2}+0.164 \mathrm{X}_{2} \mathrm{X}_{3}^{2}-$

$0.036 \mathrm{X}_{2}^{2} \mathrm{X}_{3}\left(R^{2}=0.974\right)$

$t_{50}=-462.214+69.771 X_{2}+157.457 X_{3}-7.260 X_{2} X_{3}-2.006 X_{2}^{2}-11.006 X_{3}^{2}+$

$0.552 \mathrm{X}_{2} \mathrm{X}_{3}^{2}+0.00 \mathrm{X}_{2}^{2} \mathrm{X}_{3}\left(R^{2}=0.974\right)$

$t_{75}=-2176.07+323.65 X_{2}+461.48 X_{3}-39.96 X_{2} X_{3}-10.029 X_{2}^{2}-23.829 X_{3}^{2}+$

$1.404 \mathrm{X}_{2} \mathrm{X}_{3}^{2}+0.888 \mathrm{X}_{2}^{2} \mathrm{X}_{3}\left(R^{2}=0.724\right)$

Flag $=-584.786+238.529 X_{2}+409.84 X_{3}-51.35 X_{2} X_{3}-8.934 X_{2}^{2}-29.734 X_{3}^{2}+$

$2.50 \mathrm{X}_{2} \mathrm{X}_{3}^{2}+1.050 \mathrm{X}_{2}^{2} \mathrm{X}_{3}\left(R^{2}=0.724\right)$

The above equations indicate that individual factors $X_{2}$ and $X_{3}$ show a significant $(p<0.05)$ positive effect on $t_{25}, t_{50}, t_{75}$ and Flag but their combination had a negative effect.

It followed from the systematic study, using the Box-Behnken design, that the amounts of SA, NaCMC and MAS had a significant effect $(p<0.05)$ on $t_{25}, t_{50}, t_{75}$ and Flag. Thus, by selecting a suitable concentration of the rapidly hydrating-rate-controlling polymer (SA), gel forming agent ( $\mathrm{NaCMC}$ ) and swelling-controlling agent (MAS), the desired dissolution profile can be achieved.

\section{CONCLUSIONS}

The present study involved the design of a novel gastroretentive floating and swellable, controlled-release, tablet of MS. Its comprised the release-rate-controlling hydrophilic polymers, a release modulator and a gas generating agent. Upon administration, the MSGR tablet was hydrated and swelled rapidly due to imbibition of the gastrointestinal fluid; subsequent gas generation helped the system buoyancy and the desired release profile. Optimized batch formulation MS01 showed buoyancy with Flag time less than one min (48 s) and remained floating for $16 \mathrm{~h}$. Minimum floating time and higher percetange of swelling of the MS01 formulation is required to increase its residence time in the stomach and eventually improve the extent of bioavailability. The present study confirmed the test of the suitability of gastroretentive platform technology developed for the MSGR tablet without changing any excipients and process parameters. The optimized batch MS01GR tablet, prepared using novel combinations of SA, NaCMC and MAS, can be successfully employed as a once-a-day oral controlled release drug delivery system. 


\section{REFERENCES}

1. B. N. Singh and K. H. Kim, Floating drug delivery systems: an approach to oral controlled drug delivery via gastric retention, J. Control. Rel. 63 (2000) 235-259.

2. S. Arora, J. Ali, A. Ahuja, R. K. Khar and S. Baboota, Floating drug delivery systems: a review, AAPS PharmSciTech 6 (2005) 372-390.

3. R. Bomma, R. A. S. Naidu, M. R. Yamsani and K. Veerabrahma, Development and evaluation of gastroretentive norfloxacin floating tablets, Acta Pharm. 59 (2009) 211-221; DOI: 10.2478/ v10007-009-0019-6.

4. S. T. Prajapati, L. D. Patel and D. M. Patel, Gastric floating matrix tablets: Design and optimization using combination of polymers, Acta Pharm. 58 (2008) 221-229; DOI: 10.2478/v10007-008-0006-3.

5. S. K. Mishra and K. Pathak, Formulation and evaluation of oil entrapped gastroretentive floating gel beads of loratadine, Acta Pharm. 58 (2008) 187-197; DOI: 10.2478/v10007-008-0001-8.

6. J. G. Hardman, L. E. Limbird, A. G. Gilman (Eds.), Goodman and Gilman's: The Pharmacological Basis of Therapeutics, $10^{\text {th }}$ ed., McGraw-Hill Publishers, New York 2001, pp. 255-256.

7. M. J. Kendall, S. R. Maxwell, A. Sandberg and G. Westergren, Controlled release metoprolol. Clinical pharmacokinetic and therapeutic implications, Clin. Pharmacokin. 21 (1991) 319-330.

8. G. Jobin, A. Cortot, J. Godbillon, M. Duval, J. P. Schoeller, J. Hirtz and J. J. Bernier, Investigation of drug absorption from the gastrointestinal tract of man. I. Metoprolol in stomach, duodenum, and jejunum, Br. J. Clin. Pharmacol. 19 (1985) 97-105.

9. C. Narendra, M. S. Srinath and G. Babu, Optimization of bilayer floating tablet containing metoprolol tartrate as a model drug for gastric retention, AAPS PharmSciTech. 7 (2006) 23-29; DOI: $10.1208 /$ pt070234.

10. H. Ravishankar, P. Patil, A. Samel, H-U. Petereit, R. Lizio and J. Iyer-Chavan, Modulated release metoprolol succinate formulation based on ionic interactions: in-vivo proof of concept, J. Control. Rel. 111 (2006) 65-72.

11. United States Pharmacopoeia 30, National Formulary 25, USP Convention, Rockville 2007, p. 2648.

12. M. Rosa, H. Zia and T. Rhodes, Dosing and testing in-vitro of a bioadhesive and floating drug delivery system for oral application, Int. J. Pharm. 105 (1994) 65-70; DOI: 10.1016/0378-5173 (94) 90236-4.

13. T. Higuchi, Rate of release of medicaments from ointment bases containing drugs in suspensions, J. Pharm. Sci. 50 (1961) 874-875.

14. R. W. Korsmeyer, R. Gurny, E. Doelker, P. Buri and N. A. Peppas, Mechanisms of solute release from porous hydrophilic polymers, Int. J. Pharm. 15 (1983) 25-35; DOI: 10.1016/0378-5173(83) 90064-9.

15. N. A. Peppas, Analysis of Fickian and non-Fickian drug release from polymers, Pharm. Acta Helv. 60 (1985) 110-111. 
S. P. Boldhane and B. S. Kuchekar: Development and optimization of metoprolol succinate gastroretentive drug delivery system, Acta Pharm. 60 (2010) 415-425.

$S A \check{Z} E T A K$

\section{Razvoj i optimizacija sustava za isporuku metoprolol sukcinata sa zadržavanjem u želucu}

SANJAY P. BOLDHANE i BHANUDAS S. KUCHEKAR

U radu je opisan razvoj sustava za isporuku metoprolol sukcinata (MS) s kontroliranim oslobađanjem i produljenim vremenom zadržavanja u želucu (GR), u svrhu poboljšanja bioraspoloživosti. Primijenjen je Box-Behnkenov model, a kao zavisne varijable izabrane su nove kombinacije natrijevog alginata (SA), natrijeve soli karboksimetilceluloze (NaCMC) i magnezijevog aluminometasilikata (MAS). Vrijeme plutanja (Flag), $t_{25}$, $t_{50}, t_{75}$ i difuzijski eksponent kao zavisne varijable otkrili su da količina SA, NaCMC i MAS ima značajan učinak $(p<0,05)$ na $t_{25}, t_{50}, t_{75}$ i Flag. Pripravljenim tabletama određena je masa, debljina, tvrdoća, lomljivost, sadržaj ljekovite tvari i sposobnost plutanja. Oslobađanje MS praćeno je $24 \mathrm{~h}$. Rezultati pokazuju da je oslobađanje kontrolirano, a vrijeme plutanja $16 \mathrm{~h}$. Oslobađanje iz optimiranog pripravka MS01 slijedi kinetiku pr$\operatorname{vog}$ reda $\left(R^{2}=0,9868, n=0,543\right)$, što ukazuje na difuziju koja ne slijedi Fickov zakon već anomalni transport difuzijom i bubrenjem.

Ključne riječi: metoprolol sukcinat, zadržavanje u želucu, Box-Behnkenovo dizajniranje, plutajuće tablete, kinetika oslobađanja, kontrolirano oslobađanje

Piramal Health Care Limited, Mumbai-400063, India

Maharashtra Institute of Pharmacy, Pune-411038, India 